\title{
Baerveldt Glaucoma Implant versus Ahmed Glaucoma Implant in a One-Year Follow Up, Comparative Study
}

This article was published in the following Dove Press journal: Clinical Ophthalmology

\author{
Khaled Hamdi Elbaklish (iD) \\ Safaa Mohammed Saleh \\ Wael Adel Gomaa (D) \\ Ophthalmology Department, Ain Shams \\ University, Cairo, Egypt
}

Aim: To compare clinical outcomes between Ahmed glaucoma implant (AGV-S2 and FP7 models) and Baerveldt-350 glaucoma implant (BGI).

Design: Prospective randomized study.

Methods and subjects: Eighty-one participants with glaucoma after ocular surgery or secondary glaucoma with persistent and uncontrolled IOP $>21 \mathrm{mmHg}$ were randomized for placement of BGI or AGV models using a standardized surgical technique. The primary outcome was failure, which was defined as IOP $>16 \mathrm{mmHg}$ with glaucoma medication, on 2 consecutive study visits. Secondary outcomes were IOP, medication use, visual acuity, complications, and interventions.

Results: At one-year follow up, the mean IOP was $14.76 \pm 2.5 \mathrm{mmHg}$ in BGI group and $16.57 \pm 3.35 \mathrm{mmHg}$ in $\mathrm{AGV}$ group $(\mathrm{P}=0.015)$. The mean number of glaucoma medications in use was $1.6 \pm 0.81$ in the BGI group and $3.91 \pm 0.0 .28$ in the AGV group $(\mathrm{P}<0.001)$. There was $1.81 \mathrm{mmHg}$ difference in the mean IOP between participants in both groups with 0.85 SD difference. At 12 months, the failure rate was 11/56 (19.67\%) in AGV group and 3/25 $(12 \%)$ in BGI group $(\mathrm{P}=0.352)$. The VA was stable in $77 \%$ in the $\mathrm{BGI}$ group $(\mathrm{P}=0.93)$ versus $80 \%$ of patients in $\mathrm{AGV}$ group $(\mathrm{P}=0.88)$. No significant change was observed in logMAR Snellen VA between both groups $(\mathrm{P}=0.254)$. None of the patients lost light perception.

Conclusion: Both the Ahmed valve implant and the Baerveldt implant are effective in reducing preoperative IOP and glaucoma medications in patients with refractory glaucoma. This trial cannot give clear clinical proof for valve superiority over the other. The Baerveldt350 implant can be a good choice for refractory glaucoma cases. Capsular scarring around the plate is considered as the main factor for surgical failure and resistant IOP.

Trial registration: The trial was registered with the Research Ethical Committee, Ain Shams University, FWA 000017585 FMASU 21/2017, and registered at Clinical Trial. gov: NCT04215575

Keywords: Baerveldt, Ahmed, plate, encapsulation, size

\section{Summary}

Refractory glaucoma is a difficult subject as many glaucoma devices attempt to reduce IOP. BGI is considered as a large implant, and, on the contrary, AGV is considered a small implant as many comparisons have shown. We have previously used two models, S2 and FP7 of AGV. In this study, we used BGI in refractory glaucoma cases in order to compare it with the AGV.

The failure rate was $12 \%$ in BGI group versus $19.67 \%$ in $\mathrm{AGV}$ group in one year follow up. There was $1.81 \mathrm{mmHg}$ reduction in the mean IOP in BGI
Correspondence: Khaled Hamdi Elbaklish Ophthalmology Department, Ain Shams University, Abbasi, Cairo, Egypt

Tel +201000057550

Email khaled.hamdy62@yahoo.com 
group at one year. This is considered as statistical superiority to the BGI implant without clinical superiority.

The positive values in the study were the reduced IOPs and a smaller number of medications that decreased significantly with the BGI implant. Capsular scarring around the plate was the main cause of failure in the valve surgery.

\section{Introduction}

Neovascular glaucoma, childhood glaucoma, postkeratoplasty glaucoma, extensive conjunctival fibrosis are examples of refractory glaucoma. Refractory glaucoma still needs solutions. The standard trabeculectomy cannot help these cases. Glaucoma valve surgery was introduced to help these cases. ${ }^{1}$ Medicare data reported the increasing usage of Glaucoma drainage implants (GDIs), from 1994 to 2012 (2000-12,000). In addition, there is an increasing rate of GDIs' usage in patients who had failed trabeculectomy, and those with neovascular or uveitic glaucoma in comparison with the trabeculectomy with mitomycin-C. ${ }^{2-4}$

The change in this practice pattern was achieved through the results of Tube Versus Trabeculectomy (TVT) Study, which found that the treatment outcomes after GDI surgery in patients with refractory glaucoma were much better than trabeculectomy with mitomycin-C. ${ }^{5}$

However, the valve selection could be a difficult choice. Now, Ahmed, Baerveldt and Molteno implants are the glaucoma devices being used. These implants share a common design, a tube located inside of the anterior chamber and connected to a plate at the equatorial region of the globe. ${ }^{6}$

The Committee of The American Academy reported an insufficient assessment of efficacy or complications rates of commercially available glaucoma devices. ${ }^{7}$

Aqueous shunts differ in construction and biomaterials' usage, like the valve presence that minimizes aqueous flow through the device in case the intraocular pressure (IOP) becomes too low. ${ }^{8}$

Ahmed implant (AGV) (New World Medical, Cucamonga, CA), and Baerveldt implant (BGI) 101-350 (Abbott Medical Optics, Abbott Park, IL) are currently the two most popular implants used in the state. These shunts have a different structure, the Ahmed valve implant has a valvular design to prevent postoperative hypotony. ${ }^{9,10}$

Baerveldt implant has a free flow construction without valve design. This requires the surgeon to have a temporary tube ligature in order to avoid the excessive flow onto the equatorial plate. This flow reductive step will make the Baerveldt implant's performance safe. ${ }^{5,7}$
Previous studies compared the efficacy and safety of both BGI and AGV implants in refractory glaucomas. ${ }^{11}$

Four nonrandomized small-scale studies compared AGV with BGI, without demographic similarities, which left conclusions guarded. ${ }^{11-15}$

Specifically, studies had limited IOP difference (1.2-1.3 mmHg lower in the BGI group) on less medications (0.5-0.7 in the BGI group), with more failures in the AGV group. ${ }^{16,17}$

The claimed advantage of the AGV is the constructive valve design that decreases early postoperative hypotony.

The large valve design is considered a BGI advantage, $350 \mathrm{~mm}^{2}$ versus $184 \mathrm{~mm}^{2}$ for the AGV. This may help in long-term IOP control, if one assumes that IOP control is dependent on the surface area of a plate. ${ }^{18}$

The large surface area implant (BGI) can cause occurrence of early hypotony which limits the assumption of long-term IOP control. ${ }^{19}$

Clinical use of AGV in refractory glaucoma cases was associated with high capsular scarring rate and progressive rising of IOP. ${ }^{20}$ We conducted this study to compare the failure rate, success rate, and complications of both BGI and AGV.

\section{Methods and Subjects}

This study was approved by the Ethics Committee of Ain Shams University (registration number: FWA 000017585 , FMASU R21/2017) and we obtained written informed consent according to Declaration of Helsinki.

This was a prospective randomized study. Patients with refractory glaucoma who had previous surgery or other glaucoma diagnoses were enrolled in this study and were randomized to BGI model 101-350 placement (BGI group) or an AGV model FP7 or S2 placement (AGV group). Randomization assigned 25 patients to implant $350 \mathrm{~mm}^{2}$ BGI group and 56 patients to implant $184 \mathrm{~mm}^{2}$ AGV group. All patients had their medications.

The inclusion criteria involved patients with glaucoma who underwent a previous failed trabeculectomy or other intraocular surgery. Also, patients who had secondary glaucoma and were known to have a high failure rate with trabeculectomy such as those with neovascular, uveitis, or iridocorneal endothelial syndrome-associated glaucoma, were included in the study.

The study excluded patients who lacked light perception, were unwilling or unable to give informed consent, were expected to be unavailable for follow-up visits, had previous aqueous shunt implanted in the same eye, other external 
impediment to supero-temporal drainage device implantation, presence of silicone oil, vitreous in the anterior chamber sufficient to require a vitrectomy, and uveitis associated with a systemic condition like juvenile rheumatoid arthritis, nanophthalmos, Sturge-Weber syndrome or other conditions associated with elevated episcleral venous pressure.

The participants were masked during study time through permuted variable block randomization scheme. Only 1 eye of each patient was eligible for enrollment.

Details of study patients, eligibility, and patients following the study protocol were received, edited, processed, analyzed, and stored.

The corrected visual acuity of these cases was measured in both groups. Details of Slit lamp, angle, optic disc and retinal examination were collected in both groups. Visual field examination was implemented in thirty-two participants.

\section{Patient Visits}

Follow-up visits were scheduled 1 day, 1 week, 1 month, 3 months, 6 months, and 1 year postoperatively. The primary outcome measure was failure which was defined as IOP $>16$ mmHg or less than a $20 \%$ reduction below baseline on 2 consecutive study visits, IOP $\leq 5 \mathrm{mmHg}$ on 2 consecutive study visits, reoperation for glaucoma, loss of light perception, or removal of the implant for any reason. Success was considered when the IOP was $\leq 16 \mathrm{mmHg}$ and classified as complete or qualified. Complete success required IOP $\leq 16 \mathrm{mmHg}$ during the one-year study without the use of glaucoma medications.

Qualified success allowed the target of $\mathrm{IOP} \leq 16 \mathrm{mmHg}$, to be achieved with the use of glaucoma medications.

The IOP, the use of glaucoma medications, visual acuity (VA), visual fields, bleb morphology, and rates of surgical complications were secondary outcome measures.

\section{Statistical Analysis}

\section{Demographic, Preoperative Data Were Compared Between BGI and AGV Groups}

Continuous and quantitative variables were analyzed between groups using the independent $t$-test, Mann-Whitney, while discrete and qualitative variables were analyzed using a Pearson's chi-squared test and Fisher's Exact Test.

Comparisons of preoperative and postoperative values of IOP, independent $t$-test, linear regression test, and the General Linear Model (GLM-multivariate procedure) were done.

Kaplan-Meier survival analysis for assessment and calculation was conducted along with the logrank test.
Mean and median survival times with $95 \%$ confidence intervals (CIs) were reported.

Snellen VA measurements were converted to $\log$ MAR equivalents for data analysis. The secondary outcome measures were statistically assessed with Mann-Whitney, independent $t$-test, and Cox regression analysis. I have target $16.5 \pm 5.1 \mathrm{mmHg}$ in AVG group and $13.8 \pm 4.6$ $\mathrm{mmHg}$ in BGI group in one year follow up. ${ }^{21}$ We used a sample size calculated from this study considering a study power at 0.8 with $\propto$ of 0.05 aiming to detect 3 mmHg difference in mean IOP in one-year follow up. Our study involved two unequal groups, 25 patients in BGI group and 56 patients in AGV group.

\section{Surgical Procedure}

All surgical procedures were performed under local anesthesia except for children, for whom general anesthesia was used. A $350 \mathrm{~mm}^{2}$ Baerveldt glaucoma implant was placed in the superotemporal quadrant in 25 patients randomized to BGI group. A limbus-based conjunctival flap was dissected, and the implant was sutured to sclera $10 \mathrm{~mm}$ posterior to the limbus. The Baerveldt tube was completely occluded to temporarily restrict flow through the device until encapsulation of the plate occurred. The tube was fenestrated for early IOP reduction. A scleral graft was used to cover the limbal portion of the tube, and the conjunctiva was closed.

A $184 \mathrm{~mm}^{2}$ Ahmed glaucoma implant was placed in the superotemporal quadrant in 56 patients randomized to AGV group. A fornix-based conjunctival flap was dissected, and the implant was sutured to sclera $10 \mathrm{~mm}$ posterior to the limbus. The Ahmed tube left patent and viscoelastic substance injected into anterior chamber. A scleral graft was used to cover the limbal portion of the tube, and the conjunctiva was closed.

\section{Postoperative Management}

Postoperative treatment consisted of topical prednisolone, cyclopentolate and ofloxacin eye drops. IOP became uncontrolled during the first weeks in BGI group. Glaucoma medications including acetazolamide tablets were prescribed in this period. Four weeks later, the occluded thread was removed. Removal of the occluding thread was associated with IOP reduction, IOP was around $7 \mathrm{mmHg}$. This low IOP was associated with reversible choroidal effusion without AC loss. Removal of the stitches was done 10 days after surgery. In AGV group, IOP was at low average level 
within 2-3 days after surgery with disappearance of the viscoelastic substance.

\section{Results}

\section{Patient Recruitment}

The mean follow-up period was $397.92 \pm 11.47$ days (range, 380-420 days) for BGI group and 400.26 \pm 10.87 days (range, 385-420 days) for AGV group $(\mathrm{P}=0.380)$. Eighty-one patients were involved in the study between 2012 and 2016. In BGI group, the average age was 45 \pm 5.92 years, the average age was $45.05 \pm 6.31$ years in AGV group. Baseline demographic and ocular characteristics were similar between BGI and AGV groups, Table 1.
There was no significant difference in the glaucoma types between both groups. The diagnoses were neovascular glaucoma (42\%), post keratoplasty glaucoma (4\%), OAG with repeated failure of trabeculectomies $(28 \%)$, pseudophakic glaucoma (7\%), developmental glaucoma $(5 \%)$, glaucoma after uveitis $(10 \%)$, and glaucoma after infantile cataract surgery (4\%). The previous surgeries were trabeculectomy with mitomycin-c, repeated trabeculectomies, cataract surgeries, and penetrating keratoplasty (PKP). Sixty-four percent of the patients had undergone phaco surgery, $44 \%$ of the patients had undergone trabeculectomies with mitomycin-c, and $4 \%$ of the patients had undergone penetrating keratoplasty.

Table I Demographic Data of Patients with Baerveldt-350 mm and Ahmed $184 \mathrm{~mm}^{2}$ Implants

\begin{tabular}{|c|c|c|c|}
\hline & Baerveldt-350 $(n=25)$ & Ahmed-I84(n = 56) & P Value \\
\hline Mean age in years (SD) & $45 \pm 5.92$ & $45.05 \pm 6.31$ & $0.102 *$ \\
\hline Sex, female/male & $13 / 12$ & $21 / 35$ & $0.221 * * *$ \\
\hline $\begin{array}{l}\text { Glaucoma subtype } \\
\text { Neovascular glaucoma } \\
\text { Glaucoma with prior trabeculectomy } \\
\text { procedure including } \\
\text { I-Uveitic glaucoma } \\
\text { 2-Congenital glaucoma } \\
\text { 3-Primary open angle glaucoma } \\
\text { 4-Pseudophakic glaucoma } \\
\text { 5-Glaucoma after infantile cataract surgery } \\
\text { Postkeratoplasty glaucoma }\end{array}$ & $\begin{array}{l}12(48 \%) \\
12(48 \%) \\
2 \\
2 \\
5 \\
2 \\
1 \\
I(4 \%)\end{array}$ & $\begin{array}{l}22(39.28 \%) \\
32(57.15 \%) \\
6 \\
2 \\
18 \\
4 \\
2 \\
2(3.57 \%)\end{array}$ & $0.745^{* *}$ \\
\hline $\begin{array}{l}\text { Previous ocular surgery Trabeculectomy } \\
\text { Penetrating keratoplasty } \\
\text { Cataract extraction } \pm \text { intraocular lens } \\
\text { placement }\end{array}$ & $\begin{array}{l}20 \text { (repeated surgery in eight patients + } \\
4 \text { trabeculectomies in secondary and } \\
\text { congenital glaucoma) } \\
\mathrm{I}(4 \%) \\
17(68 \%)\end{array}$ & $\begin{array}{l}34 \text { (repeated surgery in ten patients }+ \\
14 \text { trabeculectomies in secondary and } \\
\text { congenital glaucoma) } \\
2(3.57) \\
35(64 \%)\end{array}$ & $0.894 * *$ \\
\hline $\begin{array}{l}\text { Other procedures } \\
\text { Panretinal photocoagulation ranibizumab injection } \\
\text { Diode laser cycloablation }\end{array}$ & $\begin{array}{l}12 \text { cases }(48 \%) \\
40 \text { injections } \\
I(4 \%)\end{array}$ & $\begin{array}{l}18 \text { cases }(32 \%) \\
50 \text { injections } \\
I(I .7)\end{array}$ & $0.897^{* *}$ \\
\hline Preoperative PSD & 12 cases $3.192 \pm 0.808$ & 20 cases $2.305 \pm 0.460$ & $0.411 *$ \\
\hline $\begin{array}{l}\text { Preoperative IOP in } \mathrm{mmHg}(\mathrm{SD}) \\
\text { The range of IOP }\end{array}$ & $\begin{array}{l}\text { The mean IOP was } 45.00 \mathrm{mmHg} \pm 5.92 \\
55-35 \mathrm{mmHg}\end{array}$ & $\begin{array}{l}\text { The mean IOP was } 45.17 \mathrm{mmHg} \pm 6.35 \\
56-35 \mathrm{mmHg}\end{array}$ & $0.905^{*}$ \\
\hline $\begin{array}{l}\text { Glaucoma drugs used before surgery } \\
\text { (dorzolamide/timolol eye drops, latanoprost } \\
\text { eye drops, Acetazolamide tablets) }\end{array}$ & $3.88 \pm 0.33$ & $3.91 \pm 0.28$ & $0.673 *$ \\
\hline $\begin{array}{l}\text { Preoperative VA }(2 / 60-6 / 24) \text {. } \\
\text { Median } \\
\text { Interquartile Range }\end{array}$ & $\begin{array}{l}1.176 \\
0.48\end{array}$ & $\begin{array}{l}1.079 \\
0.30\end{array}$ & $0.272 * *$ \\
\hline
\end{tabular}

Notes: *Assessed by independent $t$-test. **Assessed by Mann-Whitney test. ***Assessed by chi-squared test of independence $\left(\mathrm{X}^{2}\right)$. 
$37 \%$ of the patients had undergone panretinal photocoagulation and repeated ranibizumab injection before surgery. $2 \%$ of the patients had undergone Diode laser cycloablation (Table 1).

\section{Intraocular Pressure Reduction}

At 12 months, the failure rate was 11/56 (19.64\%) in AGV group and 3/25 (12\%) in BGI group $(\mathrm{P}=0.360)$. Participants with qualified success, were $37 / 56(66.07 \%)$ at 12 months for the AGV group and 17/25 (68\%) at 12 months for the BGI group. (0.015) The reason for failure in both groups was progressive IOP rising.

The success rates were low in both groups, 8/56 $(14.28 \%)$ in AGV group and 5/25 (20\%) in BGI group ( $\mathrm{P}=0.554)$.

Figure 1 shows the mean IOPs in one-year follow up in both groups. The difference between the mean preoperative IOPs in both groups was not significant $(\mathrm{P}=0.905)$. All measurements of the postoperative mean IOPs at 1, 3, 6, 9, and 12 months were statistically significant and considerably lower in comparison with the baseline IOP $(\mathrm{P}=0.001)$ in both groups.

Both study groups had a significant postoperative reduction in IOP. At 12 months follow-up, for the AGV group, the mean IOP (on glaucoma medication) was reduced from $23.94 \pm 3.93 \mathrm{mmHg}$ (preoperative) to $16.57 \pm 3.35 \mathrm{mmHg}$ (postoperative) $(\mathrm{P}<0.001)$. In the BGI group, IOP (on glaucoma medication) was reduced from $29.4 \pm 2.59 \mathrm{mmHg}$ (preoperative) to $14.76 \pm 2.5$ $\mathrm{mmHg}$ (postoperative) at one-year follow-up $(\mathrm{P}<0.001)$.

After surgery, the difference in the mean IOP measurements between BGI and $\mathrm{AGV}$ groups was significant at first month ( -6.15 (CI -7.12,-5.18), $\mathrm{P}<0.001), 3$ months $(-3.02$ (CI-4.06,-1.98), $\mathrm{P}<0.001), 6$ months (1.75 (CI 0.31, 3.18), $\mathrm{P}=0.018)$, and at one year follow up ( -1.81 (CI-3.30,-0.316), $\mathrm{P}=0.015)$. At 9 months after surgery, the difference in the mean IOP measurements between BGI and AGV participants was insignificant $(-0.88$ (CI-2.19, 0.43), $\mathrm{P}=0.183)$.

The surgery had a significant effect which caused a difference between the mean IOPs in BGI and AGV groups in one-year follow up (Table 2).

Figure 2 shows the mean number of glaucoma medications in the BGI and AGV groups at baseline and one-year followup.

The mean number of glaucoma medications in the AGV group was reduced from $3.83 \pm 0.33$ at baseline to $2.83 \pm 1.34$ at the one-year follow-up visit (P-0.001). The mean number of glaucoma medications in the BGI group was reduced from $3.91 \pm 0.0 .28$ at baseline to $1.6 \pm 0.81$ at the one-year follow-up $(\mathrm{P}=0.001)$ (Figure 2).

\section{The mean IOP in BGI and AGV groups}

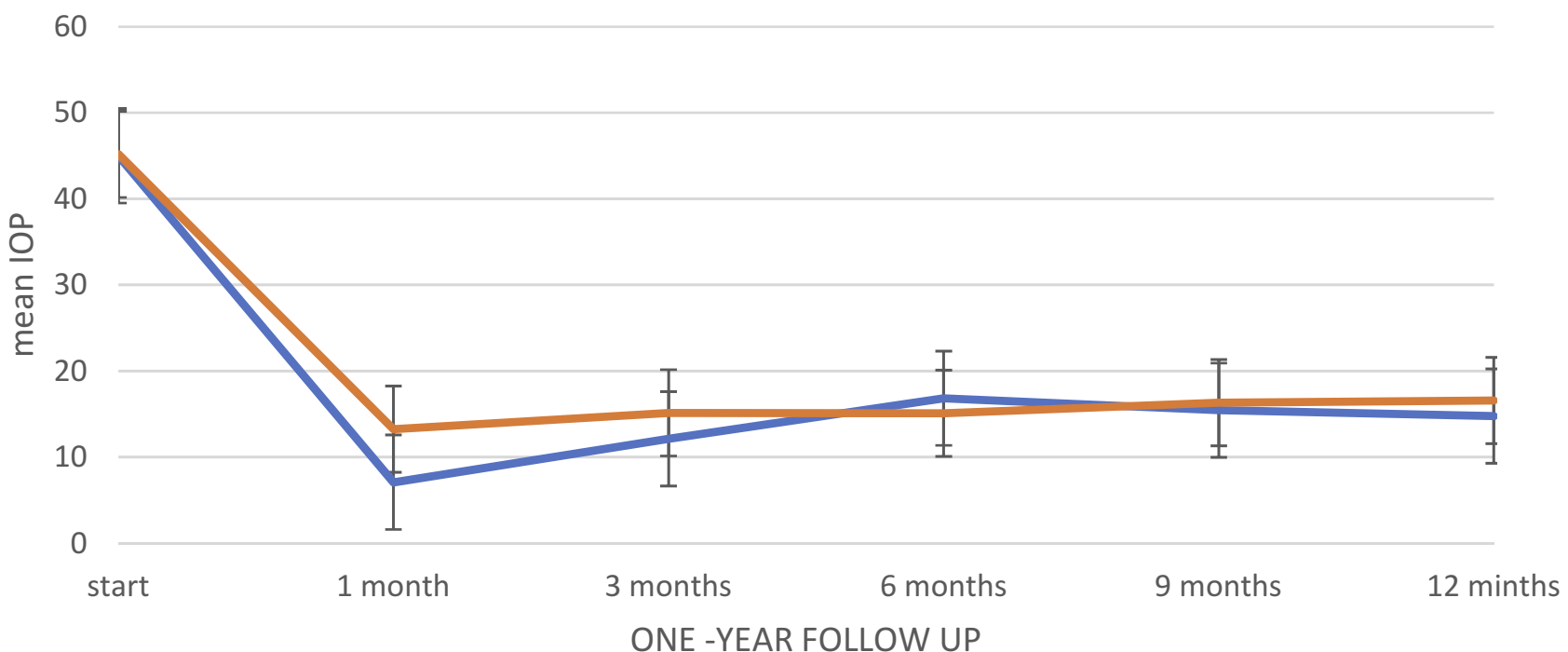

$$
\text { mean IOP in BGI group mean IOP in AGV group }
$$

Figure I Graph demonstrating the mean intraocular pressures (IOPs) \pm standard deviation after implantation of BGI and AGV devices in one-year follow-up. Error bars represent standard deviation. 
Table 2 Intraocular Pressure and Medical Therapy at Baseline and Follow-up in BGI and AGV groups

\begin{tabular}{|c|c|c|c|}
\hline IOP (mmHg; mean_tSD) (Before + After Glaucoma Medication) & BGI Group, n (\%) & AGV Group, n (\%) & $P$ Value \\
\hline Preoperative IOP & $45.00 \mathrm{mmHg} \pm 5.92$ & $45.17 \mathrm{mmHg} \pm 6.35$ & $0.905^{*}$ \\
\hline Preoperative IOP with medication & $29.4 \mathrm{mmHg} \pm 2.59$ & $23.94 \mathrm{mmHg} \pm 3.93$ & \\
\hline & $(27.98-30.82)$ & $(23.02-24.91)$ & \\
\hline & (25 cases) & (56 cases) & \\
\hline Glaucoma medications & $3.91 \pm 0.28$ & $3.88 \pm 0.33$ & $0.673 *$ \\
\hline First month postop IOP $(\mathrm{mmHg})$ without medication & $\begin{array}{l}7.08 \mathrm{mmHg} \pm 1.63 \\
(25 \text { cases })\end{array}$ & $\begin{array}{l}12.86 \mathrm{mmHg} \pm 1.77 \\
(52 \text { cases })\end{array}$ & \\
\hline First month postoperative & ( 0.00 cases $)$ & $18 \mathrm{mmHg} \pm 0.8 \mathrm{I}$ & \\
\hline IOP with medication & & (4 cases) & \\
\hline Mean IOP at first month & $\begin{array}{l}7.08 \mathrm{mmHg} \pm \mathrm{I} .63 \\
(6.27-7.89)\end{array}$ & $\begin{array}{l}13.23 \mathrm{mmHg} \pm 2.17 \\
(12.69-13.77)\end{array}$ & $0.00 * *$ \\
\hline Glaucoma medications & 0.00 & $0.14 \pm 0.51$ & $0.175 *$ \\
\hline Three months postop & $12.12 \mathrm{mmHg} \pm 1.23$ & $13.86 \mathrm{mmHg} \pm \mathrm{I} .3 \mathrm{I}$ & \\
\hline IOP $(\mathrm{mmHg})$ without medication & ( 25 cases) & (36 cases) & \\
\hline Three months postop & ( 0.00 cases $)$ & $17.45 \mathrm{mmHg} \pm 2.4 \mathrm{I}$ & $0.00 * *$ \\
\hline IOP with medication & $12.12 \mathrm{mmHg} \pm 1.23$ & (20 cases) & \\
\hline Mean IOP at third month & $(11.25-12.99)$ & $\begin{array}{l}15.14 \mathrm{mmHg} \pm 2.47 \\
(14.57-15.72)\end{array}$ & \\
\hline Glaucoma medications & 0.00 & $0.75 \pm 0.97$ & $0.001 *$ \\
\hline Six months postop & $14.6 \mathrm{I} \mathrm{mmHg} \pm 3.5 \mathrm{I}$ (13 cases) & $13.54 \mathrm{mmHg} \pm 1.35$ & \\
\hline IOP $(\mathrm{mmHg})$ without medication & & ( 24 cases) & \\
\hline Six months postop & $19.25 \mathrm{mmHg} \pm 3.5 \mathrm{I}$ & $16.25 \mathrm{mmHg} \pm 2.94$ & \\
\hline IOP with medication & (12 cases) & (32 cases) & \\
\hline Mean IOP at sixth month & $\begin{array}{l}16.84 \mathrm{mmHg} \pm 3.54 \\
(15.65-18.04)\end{array}$ & $\begin{array}{l}15.08 \mathrm{mmHg} \pm 2.73 \\
(14.29-15.89)\end{array}$ & $0.018^{* *}$ \\
\hline Glaucoma medications & $0.96 \pm 1.01$ & $1.30 \pm 1.14$ & $0.201 *$ \\
\hline Nine months postop & $13.80 \mathrm{mmHg} \pm 0.44$ & $14.81 \mathrm{mmHg} \pm 1.16$ & \\
\hline IOP $(\mathrm{mmHg})$ without medication & ( 5 cases $)$ & (I I cases) & \\
\hline Nine months postop & $15.85 \mathrm{mmHg} \pm 2.39$ & $16.68 \mathrm{mmHg} \pm 3.08$ & \\
\hline IOP with medication & (20 cases) & (45 cases) & \\
\hline Mean IOP at ninth month & $\begin{array}{l}\mathrm{I} 5.44 \mathrm{mmHg} \pm 2.29 \\
(14.35-16.53)\end{array}$ & $\begin{array}{l}16.32 \mathrm{mmHg} \pm 2.89 \\
(15.60-17.05)\end{array}$ & $0.183^{* *}$ \\
\hline Glaucoma medications & $1.6 \pm 0.8 \mathrm{I}$ & $2.48 \pm 1.42$ & $0.005^{*}$ \\
\hline Twelve months postop & $14.40 \mathrm{mmHg} \pm 0.54$ & $14.50 \mathrm{mmHg} \pm 0.92$ & \\
\hline IOP $(\mathrm{mmHg})$ without medication & ( 5 cases $)$ & (8 cases) & \\
\hline Twelve months postop & $14.84 \pm 2.79$ & $17.27 \mathrm{mmHg} \pm 3.57$ & \\
\hline IOP with medication & (20 cases) & (48 cases) & \\
\hline Mean IOP at twelve months & $\begin{array}{l}14.76 \mathrm{mmHg} \pm 2.5 \\
(13.52-16.00)\end{array}$ & $\begin{array}{l}16.57 \mathrm{mmHg} \pm 3.35 \\
(15.74-17.40)\end{array}$ & $0.015^{* *}$ \\
\hline Glaucoma medications & $1.6 \pm 0.81$ & $2.83 \pm 1.34$ & $0.001 *$ \\
\hline
\end{tabular}

Notes: *Assessed by independent $t$-test. **Assessed by GLM-multivariant and independent $t$ - test.

The mean number of glaucoma medications in BGI and AGV groups was not significantly different at first month $(\mathrm{P}=0.175)$ and 6 months $(\mathrm{P}=0.201)$. The mean number of glaucoma medications in both groups differed statistically within 3912 months $(\mathrm{P}=0.001$, $\mathrm{P}=0.005, \mathrm{P}=0.001$ ).
The glaucoma medication affected the mean IOP in BGI group and AGV group in linear regression analysis. The p-value associated with F-value was very small $(\mathrm{P}<0.001)$ at 1 month. The $\mathrm{p}$-value was 0.76 at 3 months, $\mathrm{P}=0.0 .002$ at 6 months, $\mathrm{P}=0.263$ at 9 months, and $\mathrm{P}=0.106$ at 12 months. There was a weak clinical 


\section{The number of glaucoma medication in BFI and AGV groups}

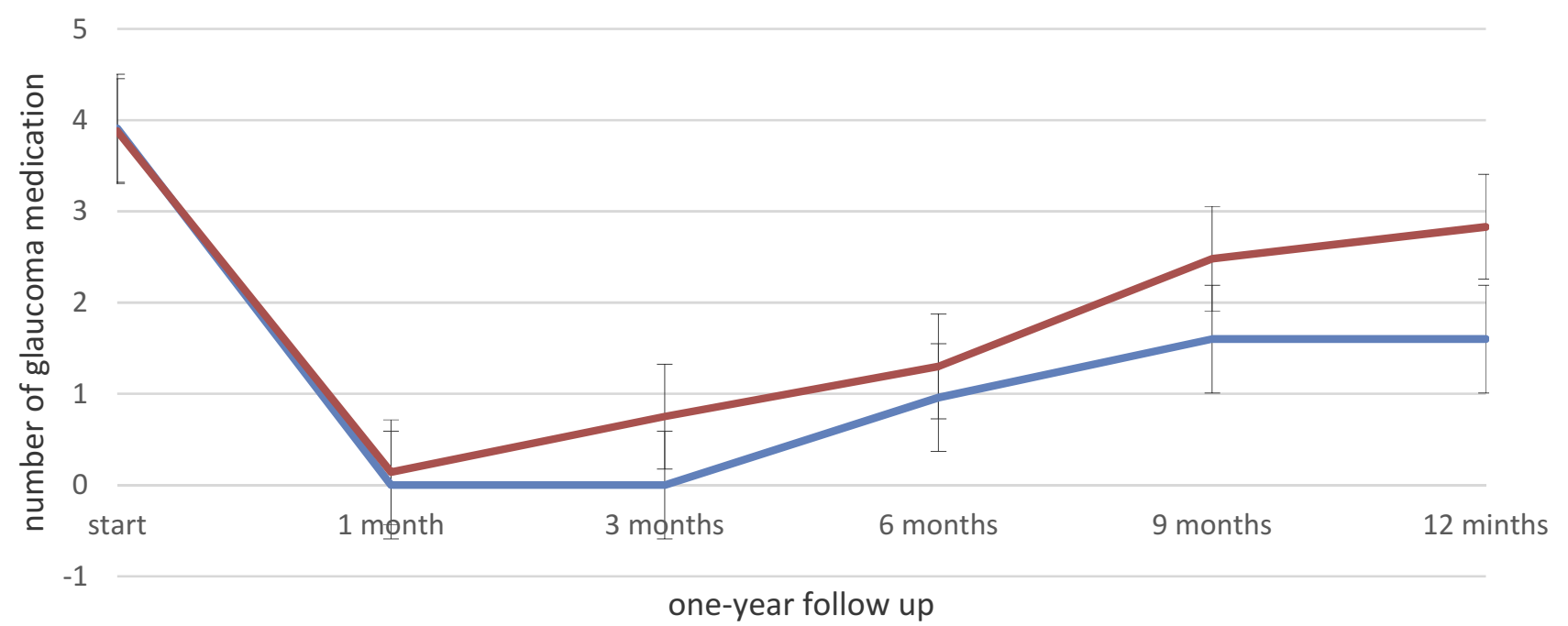

Glaucoma medications in BGI group $\quad$ Glaucoma medications in AGV group

Figure 2 Graph demonstrating the mean number of glaucoma medications \pm standard deviation after implantation of BGI or AGV in one-year follow-up. Error bars represent standard deviation.

Survival Functions of $B G I$ and $A G V$ curves

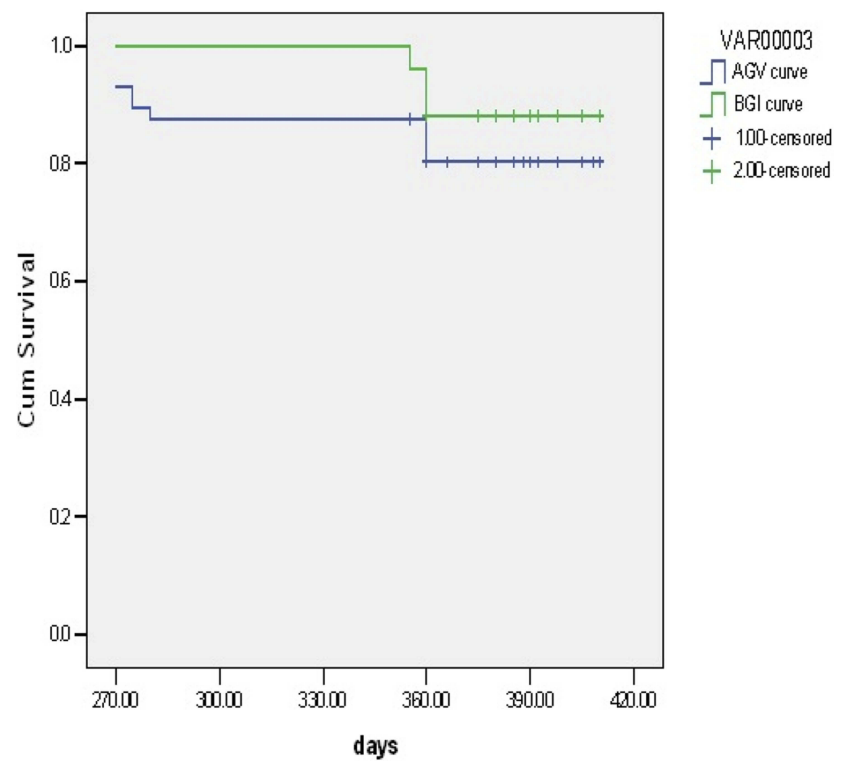

Figure 3 Kaplan-Meier survival curve of BGI and AGV groups reported $12 \%$ and $19.6 \%$ failure rate in one year follow up. The mean of BGI group was 403.80 (95\% $\mathrm{Cl}, 397.21-410.39)$, and the mean of AGV group was $389.21(95 \% \mathrm{Cl}, 377.19$ 40I.23). (0.364).

effect of glaucoma medication on the mean IOPs in BGI and AGV groups in one-year follow up.

In survival analysis, the failure started at 270 days in AGV group. The mean time to event of AGV group was 389.21 days
(95\% CI, 377.19-401.23), and the mean time to event of BGI group was 403.80 days (95\% CI, 397.21-410.39), ( $\mathrm{P}=0.364$, longrank-test), Figure 3.

\section{Visual Acuity}

The baseline corrected visual acuity of these cases was between $2 / 60-6 / 24$ in both groups. At the last visit, the VA was stable in $75 \%-80 \%$ of patients in both groups. None of the patients lost light perception.

In BGI group, twenty cases $(80 \%)$ had stable visual acuity during one year after surgery. Two cases (8\%) had improved one-line in visual acuity. Three cases (12\%) had one-line loss in visual acuity.

In AGV group, five cases had one-line improvement (8.9\%), eight cases had one-line deterioration (14.28\%), and forty-three cases had stable visual acuity (76.78\%). Figures 4 and 5 showed the changes in visual acuity before surgery and one year after surgery.

In the BGI group, log MAR Snellen median and interquartile range values decreased from 1.176, 0.48 at baseline to $1.176,0.44$ at one-year follow-up ( $\mathrm{P}=0.937)$.

In the AGV group, logMAR Snellen median and interquartile range values decreased from 1.079, 0.30 at baseline to $1.176,0.30$ at one-year follow-up visit $(\mathrm{P}=0.885)$. This difference in $\log$ MAR Snellen VA between both groups at one year was not statistically significant $(\mathrm{P}=0.254)$. 


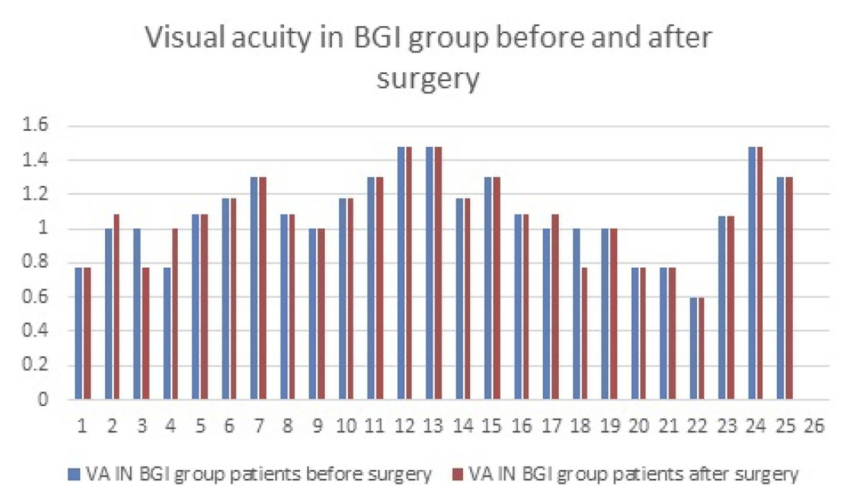

Figure 4 LogMAR chart shows the visual acuity changes before and after surgery in BGI group.

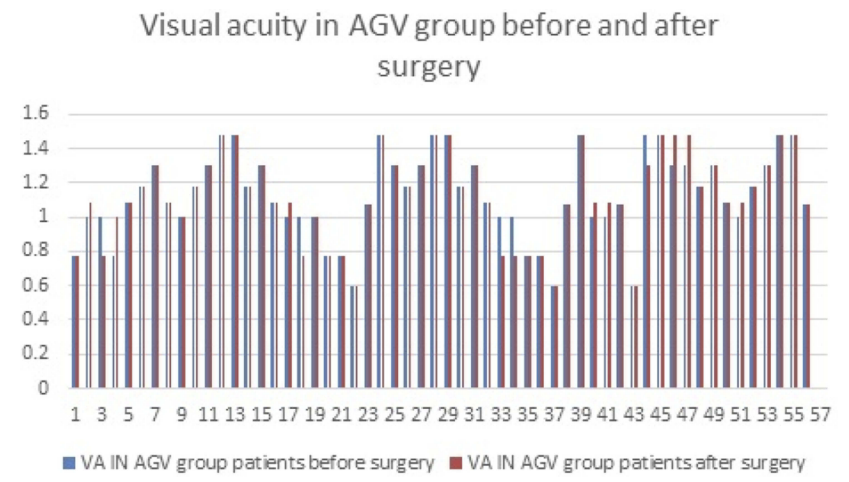

Figure 5 LogMAR chart shows the visual acuity changes before and after surgery in AGV group.

\section{Visual Fields}

In the baseline visual field examination, 16 cases had advanced generalized depression, high mean deviation (MD) and low pattern standard deviation (PSD) (tubular field, and tubular field with splitting of the fixation area). Field had marked generalized depression; no variability among the points was detected. The range of MD varied between $-14 \mathrm{Db},-26 \mathrm{~dB}$ and the range of PSD varied between $3 \mathrm{~dB}, 5 \mathrm{~dB}$. Another sixteen cases had generalized depression, prominent localized defects, high MD and high PSD (concentric contraction of the visual field). The range of MD with localized defects was $-10 \mathrm{~dB},-16 \mathrm{~dB}$, and the range of PSD was $7 \mathrm{~dB}, 12 \mathrm{~dB}$.

Three, six, nine, and twelve months after surgery, there was no real perimetric changes in twenty-six cases in both groups. Six cases, five in AGV group and a single case in BGI group, were suffered. They had stable MD, and decreased PSD (7.2 dB,12 0.1dB) $(\mathrm{P}=0.434)$.

\section{Surgical Complications}

Complications associated with BGI and AGV procedures were recorded. Choroidal effusion and hypotony after removal of the thread occurred in twenty-three cases 23/ $25(92 \%)$ in BGI group. This effusion was not associated with loss of anterior chamber depth or deterioration of visual acuity. Low peripheral choroidal effusion was improved by prednisolone drops, and cyclopentolate drops. Early postoperative hyphema was detected in eight patients of AGV group 8/56 (14.2\%) and improved within two weeks. Conjunctival bleb above the plate was flattened, greyish white and the plate borders could be delineated in ten cases of AGV group 10/56 (17.8\%). Dellen formation was detected in one case that had corneal graft in AGV group $1 / 56(1.78 \%)$. Late tube exposure was detected in six cases $6 / 56(10.7 \%)$ and treated with regrafting procedure in AGV group. Late corneal edema developed after surgery in two cases $2 / 56(3.5 \%)$ in AGV group. No early or late suprachoroidal hemorrhage was found or motility disorders detected after surgery in BGI and AGV groups.

We estimated Cox proportional hazards regression model. The parameter estimates are presented in Table 3 with their p-values. There was a positive association between surgery and choroidal detachment $(\mathrm{P}=0.005)$. Hyphema, tube

Table 3 Outcomes and Postoperative Complications after Implantation of the Baerveldt Glaucoma Valves or Ahmed Glaucoma Valves

\begin{tabular}{|c|c|c|c|}
\hline $\begin{array}{l}\text { Outcome } \\
\text { Variables }\end{array}$ & $\begin{array}{l}\text { BGI Group, } \\
\text { n (\%) }\end{array}$ & $\begin{array}{l}\text { AGV Group, } \\
\text { n (\%) }\end{array}$ & $P$ Value \\
\hline $\begin{array}{l}\text { Visual acuity after } \\
\text { surgery }\end{array}$ & & & . \\
\hline Median & 1.176 & 1.176 & $0.254 * *$ \\
\hline Interquartile Range & 0.44 & 0.30 & \\
\hline PSD after surgery & $3.200 \pm .810$ & $2.235 \pm .464$ & $0.434^{*}$ \\
\hline $\begin{array}{l}\text { Postoperative } \\
\text { choroidal } \\
\text { detachment }\end{array}$ & \multicolumn{2}{|l|}{$\begin{array}{l}23 \text { cases } 0.00 \\
\operatorname{Exp}(B) 30.442\end{array}$} & $0.005^{* * *}$ \\
\hline $\begin{array}{l}\text { Postoperative } \\
\text { hyphema }\end{array}$ & \multicolumn{2}{|c|}{$\begin{array}{l}0.008 \text { cases } \\
\operatorname{Exp}(B) 852625.21\end{array}$} & $0.980 * * *$ \\
\hline $\begin{array}{l}\text { Flattened } \\
\text { conjunctival bleb }\end{array}$ & \multicolumn{2}{|c|}{$\begin{array}{l}0.0010 \text { cases } \\
\operatorname{Exp}(B) 893932.35\end{array}$} & $0.978 * * *$ \\
\hline Tube exposure & \multicolumn{2}{|c|}{$\begin{array}{l}0.006 \text { cases } \\
\operatorname{Exp}(B) 1066513.26\end{array}$} & $0.983 * * *$ \\
\hline
\end{tabular}

Notes: *Assessed by independent $t$-test. **Assessed by Mann-Whitney test. ***A Assessed by Cox regression analysis. 
exposure, and bleb morphology did not have a positive association in proportional hazards regression model.

\section{Discussion}

Both BGI and AGV devices were good in reducing the baseline IOP, preserving vision, and reducing medication. When comparing the efficacy of both devices at one year, BGI had $1.81 \mathrm{mmHg}$ significant reduction in mean IOP. The interaction between the surgery and valve types (the variables) with the baseline IOP was great. The interaction between valve types and the difference between the postoperative IOP measures in both groups was weak. The time of starting glaucoma medications and glaucoma medication numbers were the main factors that changed the mean IOP in the study. Despite the significant difference between medication numbers in both groups, the clinical effect of glaucoma medications on the difference in the mean IOPs was weak. The reduction in valve function was associated with less clinical difference in the mean IOP between the BGI and AGV groups. Still, the BGI had a good effect on the mean IOP compared with the AGV during one-year follow-up. An IOP target of $\leq 16 \mathrm{mmHg}$ was selected based on previous glaucoma work data reporting that higher pressures should be controlled to avoid progressive optic damage, and this study's participants required more than $30 \%$ reduction in IOP to achieve this aim. ${ }^{24}$ IOP is used as the primary outcome for interventional glaucoma trials. It is objective, quantitative, and can be used clinically to monitor response to treatment. However, the aim of glaucoma therapy is preservation of vision and not reaching certain values of IOP. The reduced IOP level and medications used are related to larger plate size (Baerveldt implant$350 \mathrm{~mm}^{2}$ ) versus the small plate size (Ahmed implant$184 \mathrm{~mm}^{2}$ ). The clinical trials have shown the relation between plate size and aqueous flow. ${ }^{18,19,26}$

The different results among several studies of glaucoma devices are related to the study population differences, glaucoma subtypes, and definitions of success or failure. $^{22}$ Appropriately powered randomized controlled trials are considered the best study design for comparing the success and failure rates of both treatments. ${ }^{23}$

In our study, the success rate of AGV group was $80.4 \%$ compared with $88 \%$ in BGI group at one years follow-up. In Heuer et al's study, the success rates were reported as $73 \%$ for Baerveldt implant versus $62 \%$ for Ahmed valve implant at 12 months. ${ }^{18}$ The AGV and BGI implants could reduce the mean preoperative IOP, and the IOP reduction power ranged between $30 \%-50 \%$, which is acceptable compared with the previous glaucoma devices studies. ${ }^{25}$

Plate encapsulation is a natural reaction (foreign body reaction). The polypropylene plate (AVG, S2 implant) has a higher incident rate of tenon's cyst formation and hypertensive phase. ${ }^{22}$ The silicone material (AVG, FP7 implant) is not inert enough to prevent cyst formation. ${ }^{27}$ The reaction around the BGI plate (bleb encapsulation) has a late maturity during the first year follow up. ${ }^{28}$

If there is a late IOP elevation and the tube inside anterior chamber is seen patent, it reflects a thick fibrous capsule around the plate. ${ }^{29}$ If an eye can tolerate BGI implant surgery during the first weeks without hypotony, then the eye will have relatively stable IOP. Despite the previous statement, progressive capsular fibrosis limits the aqueous drainage through the plate to subconjunctival vessels. So, the first year of follow up is the critical period.

The size of Ahmed valve is efficient, if there is no plate encapsulation. The inflammatory reaction around the silicone plate is considered rare to have early thick encapsulation. The thickness of the plate encapsulation is the important factor rather than size of the plate. There is a difference in the biomaterials used for valve construction. The plate material in BGI is silicone while the plate material in AGV is polypropylene/silicone which induces plate pericapsular scarring. FP7 valve $(2.1 \mathrm{~mm}$ plate thickness silicone type) is thicker than $\mathrm{S} 2$ valve (1.6 mm plate thickness - polypropylene type). BGI plate has $1 \mathrm{~mm}$ plate thickness, and flexibility. The thicker silicone plate (FP7 implant) may help in tissue sensitization and foreign body reaction. Valve encapsulation and glaucoma medications' interaction with IOP are the forced predictors that can significantly change the mean IOP and surgical success.

In our study, valve encapsulation was responsible for failure (12\%-19.64\%) and starting of glaucoma medication in both BGI and AGV groups.

Although choroidal effusion and hypotony after removal of threads occurred with higher frequency $(90 \%)$ compared with other studies, ${ }^{6,21}$ they were transient and disappeared in all cases in less than two weeks. Importantly, patients neither required surgical intervention nor suffered from permanent hypotony.

With BGI, transient hypotony usually happens because the valve has a large surface area and good plate encapsulation takes a long time to occur.

Visual acuity was nearly stable in BGI and AGV groups in one-year study. Refractory glaucoma is associated with visual loss as glaucoma is mostly associated with other 
ocular diseases. So, the follow up rules are IOP measuring and visual acuity. This is preferred over fundus examination and perimetric assessment. ${ }^{31}$ Following up with disc mapping and visual field could be difficult and unwise. ${ }^{31}$

Double Ahmed valve implantation is considered risky. It is a longer, tough surgery with possible unpredictable complications like over-filtration, late rise IOP with valve encapsulation and subconjunctival fibrosis. The BGI design facilitates implantation of large surface area implant through limited limbal conjunctival incision. The plate with large surface area affords good IOP control with less medications. ${ }^{30}$ In our study, late corneal edema was detected in $\mathrm{AGV}$ participants. It may be related to the uncontrolled high IOP after surgery.

\section{Study Limitation}

There are certain limitations that should be noted when the results of the study are evaluated.

The surgeons and assessors were not blinded to the implant type. However, the participants were randomly assigned. Thus, bias is unlikely to have had a major effect on the outcomes.

IOP is a measure used to assess glaucoma treatment and it is quantifiable. The aim of glaucoma therapy is vision saving. Unfortunately, the baseline visual acuity of the patients was poor to allow good perimetric studies. Assessing of glaucomatous cupping as a treatment outcome was not possible because of absence of standardized means of comparison. Although the follow up period was relatively short ( 1 year), the most serious postoperative complications and glaucoma changes, occur in the first year. Follow up period should be extended.

\section{Conclusion}

Both the Ahmed valve implant and the Baerveldt implant are effective in reducing the preoperative IOP and glaucoma medications in patients with refractory glaucoma. This trial cannot give clear clinical proof for valve superiority over the other. Baerveldt-350 implant can be a good choice for refractory glaucoma cases. Capsular scarring around the plate is considered as the main factor for surgical failure and resistant IOP.

\section{Abbreviations}

BGI, Baerveldt 101-350 Glaucoma Implant; AGV, Ahmed implant; IOP, Intraocular pressure; VA, Visual Acuity; GDIs, Glaucoma drainage implants; TVT, Tube Versus Trabeculectomy; OAG, Open angle glaucoma; PKP, penetrating keratoplasty; $\mathrm{C} / \mathrm{D}$, Cup/disc ratio; $\mathrm{MD}$, mean deviation; PSD, pattern standard deviation; NLP, No light perception; GLM, General Linear Model; CIs, confidence intervals.

\section{Acknowledgment}

Special thanks to Prof. Osama Raslan for his support and the training provided.

\section{Disclosure}

The authors report no conflicts of interest in this work.

\section{References}

1. Emerick G, Gedde S, Budenz D. Tube fenestrations in baerveldt glaucoma implant surgery: 1-year results compared with standard implant surgery. J Glaucoma. 2002;11:4. doi:10.1097/00061198-200 208000-00011

2. Chen PP, Yamamoto T, Sawada A, et al. Use of antifibrosis agents and glaucoma drainage devices in the American and Japanese Glaucoma Societies. J Glaucoma. 1997;6:192-196. doi:10.1097/000 61198-199706000-00010

3. Joshi AB, Parrish RK II, Feuer WF. 2002 survey of the American Glaucoma Society: practice preferences for glaucoma surgery and antifibrotic use. J Glaucoma. 2005;14:172-174. doi:10.1097/01.ijg.0 000151684.12033.4d

4. Desai MA, Gedde SJ, Feuer WJ, et al. Practice preferences for glaucoma surgery: a survey of the American Glaucoma Society in 2008. Ophthalmic Surg Lasers Imaging. 2011;42:202-208. doi:10.39 28/15428877-20110224-94

5. Gedde SJ, Schiffman JC, Feuer WJ; Tube Versus Trabeculectomy Study Group. et al. Treatment outcomes in the Tube Versus Trabeculectomy (TVT) Study after five years of follow-up. Am J Ophthalmol. 2012;153:789-803.

6. Budenz D, Barton K, Feuer W, et al. Treatment outcomes in the Ahmed Baerveldt comparison study after 1 year of follow-up. Ophthalmology. 2011;118:443-452. doi:10.1016/j.ophtha.2010.07. 016

7. Minckler DS, Francis BA, Hodapp EA, et al. Aqueous shunts in glaucoma: a report by the American Academy of Ophthalmology. Ophthalmology. 2008;115:1089-1098. doi:10.1016/j.ophtha.2008.03. 031

8. Tsai JC, Johnson CC, Dietrich MS. The Ahmed shunt versus the Baerveldt shunt for refractory glaucoma: a single- surgeon comparison of outcome. Ophthalmology. 2003;110:1814-1821. doi:10.1016/ S0161-6420(03)00574-8

9. Ayyala RS, Zurakowski D, Smith JA, et al. A clinical study of the Ahmed glaucoma valve implant in advanced glaucoma. Ophthalmology. 1998;105:1968-1976. doi:10.1016/S0161-6420(98) 91049-1

10. Tsai JC, Johnson CC, Kammer JA, Dietrich MS. The Ahmed shunt versus the Baerveldt shunt for refractory glaucoma II: longer-term outcomes from a single surgeon. Ophthalmology. 2006;113:913-917. doi:10.1016/j.ophtha.2006.02.029

11. Syed HM, Law SK, Nam SH, et al. Baerveldt-350 implant versus Ahmed valve for refractory glaucoma: a case-controlled comparison. J Glaucoma. 2004;13:38-45. doi:10.1097/00061198-200402000-00 008

12. Johnson CC, Dietrich M, Tsai JC. Baerveldt shunt vs. Ahmed shunt for refractory glaucoma: a single surgeon comparison of outcome. IVOS. 2001;42:S552. 
13. Wirostko WJ, Mieler WF, Levin DS, et al. Hypotony and retinal complications after aqueous humor shunt implantation: the 1999 Dohlman Lecture. Int Ophthalmol Clin. 2000;40:1-12. doi:10.1097/ 00004397-200001000-00003

14. Roy S, Ravinet E, Mermoud A. Baerveldt implant in refractory glaucoma: long-term results and factors influencing outcome. Int Ophthalmol. 2001;24:93-100. doi:10.1023/A:1016335313035

15. Topouzis F, Coleman AL, Choplin N, et al. Follow-up of the original cohort with the Ahmed glaucoma valve implant. Am J Ophthalmol. 1999;128:198-204. doi:10.1016/S0002-9394(99)00080-X

16. Barton K, Feuer WJ, Budenz DL; Ahmed Baerveldt Comparison Study Group, et al. Three-year treatment outcomes in the Ahmed Baerveldt comparison study. Ophthalmology. 2014;121:1547-1557.

17. Christakis PG, Tsai JC, Kalenak JW, et al. The Ahmed versus Baerveldt study: three-year treatment outcomes. Ophthalmology. 2013;120:2232-2240. doi:10.1016/j.ophtha.2013.04.018

18. Heuer DK, Lloyd MA, Abrams DA, et al. Which is better? One or two? A randomized clinical trial of single plate versus double plate Molteno implantation for glaucoma in aphakia and pseudophakia. Ophthalmology. 1992;99:1512-1519. doi:10.1016/S0161-6420(92)31772-5

19. Lloyd M, Baerveldt G, Fellenbaum P, et al. Intermediate term results of a randomized clinical trial of the 350 - versus the $500-\mathrm{mm}^{2}$ Baerveldt implant. Ophthalmology. 1994;101:1456-1463. doi:10.101 6/S0161-6420(94)31152-3

20. Huang $M$, Netland $P$, Coleman A, et al. Intermediate-term clinical experience with the Ahmed glaucoma valve implant. $\mathrm{Am}$ J Ophthalmol. 1999;127:27-33. doi:10.1016/S0002-9394(98)00394-8

21. Panos GC, Jeffrey WK, James CT, et al. The Ahmed versus Baerveldt study, five-year treatment outcomes. Ophthalmology. 2016;123:2093-2102. doi:10.1016/j.ophtha.2016.06.035

22. Netland P, Costa V, Shiroma L, Khan B, Ahmed I. Comparison of polypropylene and silicone Ahmed glaucoma valves. Ophthalmology. 2006;113::1320-1326. doi:10.1016/j.ophtha.2006.04.020

23. CHRISTAKIS P, ZHANG D, BUDENZ D, et al. Five-year pooled data analysis of the Ahmed Baerveldt comparison study and the Ahmed versus Baerveldt study. Am J Ophthalmol. 2017;17 6:118-126. doi:10.1016/j.ajo.2017.01.003
24. The Advanced Glaucoma Intervention Study (AGIS). 7. The relationship between control of intraocular pressure and visual field deterioration. The AGIS investigators. Am J Ophthalmol. 2000;13 0:429-440. doi:10.1016/S0002-9394(00)00538-9

25. Gedde SJ, Panarelli JF, Banitt MR, Lee RK. Evidenced-based comparison of aqueous shunts. Curr Opin Ophthalmol. 2013;24:87-95. doi:10.1097/ICU.0b013e32835cf0f5

26. Lloyd MA, Baerveldt G, Fellenbaum PS, et al. Intermediate-term results of a randomized clinical trial of the 350 - versus the $500-\mathrm{mm}^{2}$ Baerveldt implant. Ophthalmology. 1994;101:1456-1464. doi:10.1016/ S0161-6420(94)31152-3

27. Thieme H, Choritz L, Rummelt C, Schrehardt U, Kottler U. Histopathologic findings in early encapsulated Blebs of young patients treated with the Ahmed glaucoma valve. J Glaucoma. 2011;20:246-251. doi:10.1097/IJG.0b013e3181e080ef

28. Siegner S, Netland P, Urban R, et al. Clinical experience with the Baerveldt glaucoma drainage implant. Ophthalmology. 1995; 102:1298-1307. doi:10.1016/S0161-6420(95)30871-8

29. Lai M, Poon Y, Chua H, Tham Y, Leung S, Lam C. Efficacy and safety of the Ahmed glaucoma valve implant in Chinese eyes with complicated glaucoma. Br J Ophthalmol. 2000;84:718-721. doi:10. 1136/bjo.84.7.718

30. Lloyd M, Baerveldt G, Heuer D, Minckler D, Martone J. Initial clinical experience with the Baerveldt implant in complicated glaucomas 1. Ophthalmology. 1994;101:640-650. doi:10.1016/S0161-642 0(94)31283-8

31. Souza C, Tran D, Loman J, Law S, Colman A, Caprioli J. Long-term outcomes of ahmed glaucoma valve implantation in refractory glaucomas. Am J Ophthalmol. 2007;144:893-900. doi:10.1016/j.ajo. 2007.07 .035
Clinical Ophthalmology

\section{Publish your work in this journal}

Clinical Ophthalmology is an international, peer-reviewed journal covering all subspecialties within ophthalmology. Key topics include: Optometry; Visual science; Pharmacology and drug therapy in eye diseases; Basic Sciences; Primary and Secondary eye care; Patient Safety and Quality of Care Improvements. This journal is indexed on PubMed
Dovepress

Central and CAS, and is the official journal of The Society of Clinical Ophthalmology (SCO). The manuscript management system is completely online and includes a very quick and fair peer-review system, which is all easy to use. Visit http://www.dovepress.com/ testimonials.php to read real quotes from published authors. 